\title{
Recognition of a two-element song in the grasshopper Chorthippus dorsatus (Orthoptera: Gomphocerinae)
}

\author{
Andreas Stumpner ${ }^{1}$ and Otto von Helversen \\ Institut für Zoologie II, Friedrich-Alexander Universität Erlangen-Nürnberg, Staudtstr. 5, W-8520 Erlangen, FRG
}

Accepted June 6, 1992

Summary. Males of the grasshopper Chorthippus dorsatus produce songphrases which contain two differently structured elements - pulsed syllables in the first part (A) and ongoing noise in the second part (B). Females of $C h$. dorsatus answer to artificial song models only if both elements $A$ and $B$ are present. Females strongly prefer song models in which the order of elements is A preceding $B$. Females discriminate between the two elements mainly by the existence of gaps within A-syllables. Pulses of 5-8 ms separated by gaps of 8-15 ms make most effective A-syllables, while syllable duration and syllable intervals are less critical parameters. Females respond to models which contain more than $3 \mathrm{~A}$-syllables with high probability. Female model preferences lie well in the range of parameter values produced by singing males, except for B-parts which must be longer than those of any natural song to be most effective. In ancestors of $C h$. dorsatus the two elements of the songs might have been directed towards females (part A) and males (part B).

Key words: Acoustic communication - Complex song Temporal pattern recognition - Importance of order of elements - Supernormal stimulus

\section{Introduction}

In many insect and anuran acoustic communication systems males produce conspicuous calling songs. Whereas, in many cases, these songs consist of only one element type which is repeated with a specific repetition rate, in some species the songs are composed of different element types. In these cases, the elements may be destined for different receivers: in the frog Eleutherodactylus coqui males respond mainly to the first note "co" of the twonote song, while female phonotaxis is elicited exclusively

${ }^{1}$ Present address: Institut für Zoologie I, Berliner Str. 28, W-3400 Göttingen, FRG

Correspondence to: Dr. Andreas Stumpner by the second note "qui" (Narins and Capranica 1976, 1978). Calling songs of the cricket Teleogryllus oceanicus also consist of two distinctly different elements, "chirp" and "trill". T. oceanicus females prefer song models comprising chirps but no trills over $100 \%$ trill models, while males show the reversed preference (Pollack and Hoy 1979, 1981; Pollack 1982). Also, in the seventeen-year cicada Magicicada cassini the first calling song element "tick" obviously is used for synchronizing male chorusing, while the second element "buzz" effectively elicits phonotaxis in females (Huber et al. 1990).

In addition to frogs, crickets and cicadas, many species of grasshoppers have evolved complex acoustic communication systems, especially in the subfamily Gomphocerinae within the Acrididae (Faber 1953, 1957; Elsner 1974). Since receptive females may respond to the calling songs of the males with song phrases of their own (Jacobs 1953), grasshoppers are well suited for similar investigations as in frogs and crickets. The female response songs can be elicited by artificial song models (von Helversen 1972) and can be picked up and monitored under computer control (von Helversen and von Helversen 1983). This makes it possible to analyse which of the species-specific features of the male songs are evaluated by the female recognizing mechanism [for review see von Helversen and von Helversen (1987)]. However, such studies have been carried out only for species with relatively simple songs in which the same element type is repeated stereotypically. Some species, however, have songs with two (or more) different elements which are produced in a specific order, e.g. in the genus Syrbula (Otte 1972), or in the Chorthippus albomarginatus group (von Helversen 1986). The songs of Chorthippus dorsatus and related species (e.g. Faber 1932; Jacobs 1953; Komarova and Dubrovin 1973; Schmidt and Schach 1978) comprise two differently patterned elements, a pulsed syllable (part A) and a continuous noise (part B, see Fig. 1). Besides some results presented by Vedenina (1990) and Vedenina and Zhantiev (1990), the female's recognizing mechanism of these species has not been investigated in detail. 
In this study the two-element song of $C h$. dorsatus was investigated to answer the following questions: do female Ch. dorsatus discriminate between the two different song elements? If they do, which are the decisive parameters for that discrimination? Is the presence of both elements necessary to elicit a female's response? If so, is the order of the elements of importance?

\section{Material and methods}

Animals. The grasshoppers were captured in the field, mainly as subadult nymphs to obtain virgin females. Females originated from S. Germany, N. Italy and N. Greece. Songs of males from S. Germany, Italy, Hungary, Greece and Turkey were evaluated for song parameters (Table 1).

The animals were kept in $90-1$ or 7-1 cages and supplied with fresh grass (Dactylis glomerata) on a daily basis. The light/dark cycle (light from $60-\mathrm{W}$ bulbs) was about $12 / 12 \mathrm{~h}$. All animals were individually marked with colour pens (Faber-Castell; Unipaint) before they were tested for the first time.

Song recordings. Leg movements during stridulation were recorded with an optoelectronic camera (von Helversen and Elsner 1977) simultaneously with the sound, which was picked up with a Brüel and $\mathrm{Kjaer}$ condenser microphone and $\mathrm{a} \mathrm{B}$ and $\mathrm{K}$ amplifier type 2606. The signals were stored on tape (Racal store 4DS), digitized (Data Translation card and Turbolab, Stemmer), filtered (sound $2-8 \mathrm{kHz}$ high pass, leg movements $100 \mathrm{~Hz}$ low pass) and printed.

Song recognition of females. For the behavioural experiments the females were placed in a small cage $(5 \times 5 \times 5 \mathrm{~cm})$ with a bundle of fresh-cut grass and a pod with moist sand. The cage was inside an anechoic chamber at a constant temperature of $30^{\circ} \mathrm{C}$. The speaker (Motorola piezo, 2-40 kHz) was fixed $20 \mathrm{~cm}$ from the cage. The stimuli were generated by a computer (Data General Nova 2 or $4 X$ ) modulating the output of a noise generator $(100 \mathrm{~Hz}-100 \mathrm{kHz}$, Noizeg). The female's response was picked up by a microphone, digitized by means of a Schmitt-trigger and analysed by a logic board in such a way that other sounds (e.g. from eating) could be excluded. For more details of the setup see von Helversen and von Helversen (1983).

The intensity of the stimuli was calibrated with a Brüel and Kjaer $1 / 2$ " microphone and $\mathrm{a} B$ and $\mathrm{K}$ measuring amplifier (type 2602 ) to values between 65 and $75 \mathrm{~dB}$. The stimuli consisted of rectangularly modulated white noise. An artificial song phrase was presented three times with at least 5-s intervals (depending on the duration of the female's response) and a 1-min period between different stimulus types. A stimulus, highly effective in another species (Ch. biguttulus) served as a control stimulus.

The relative number of stimuli (units of a three times repeated song phrase) which elicited a response was evaluated. Since the motivation of the females and therefore the absolute level of response frequencies may vary between days and between individuals, all values to be directly compared were measured within one stimulus program. Such a stimulus program comprised 10-18 different stimulus types presented in a pseudo-random order. For X-Y plots response functions obtained from a single female were normalized (peak value $=100 \%$ ) and the results (Fig. 2) presented as means of different females. The standard deviations given represent the variability between individual females. Statistical comparisons were made with the actual numbers of answered stimuli using a chi-square homogeneity test (Sachs 1984).

\section{Results}

\section{The calling song of the Ch. dorsatus male}

During stridulation gomphocerine grasshoppers rub stridulatory pegs on the hindleg femur against an elevated vein of the forewing thus producing a broadband signal. One phrase of a calling song of a $\mathrm{Ch}$. dorsatus male (Fig. 1, left $t$ ) lasts for about $1.5 \mathrm{~s}$ (for detailed values see Table 1; all values given for temperatures between 29 and $34{ }^{\circ} \mathrm{C}$ ). A phrase starts with the hindlegs moving nearly simultaneously. While the upstrokes produce a low-intensity sound, simultaneous stepwise movements during the downstrokes elicit pulses of 7-13 ms duration which are separated by gaps of 4-11 ms duration (Table 1). In the course of one downstroke five to seven pulses comprise "A-syllables". After three to seven of these A-syllables have been repeated with about 100 -ms upstroke intervals (Table 1), a sudden change of leg coordination occurs with both hindlegs now moving alternately at about double the previous speed (Fig. 1). Now both upstroke and downstroke produce a more or less continuous noise of similar intensity without regular

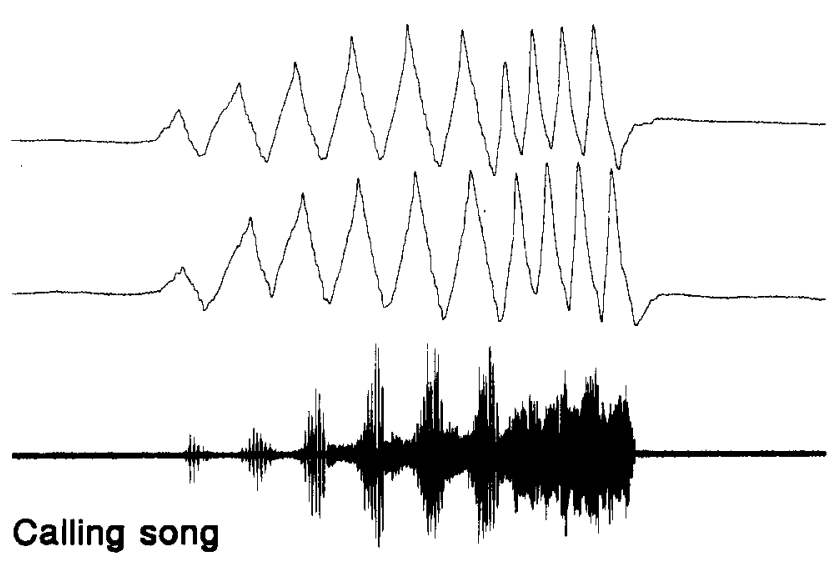

Fig. 1. Calling song and rivalry song of males of Ch. dorsatus. The upper two traces in each case represent the movements of the two hindlegs, the lower trace represents the sound. The sound in part A

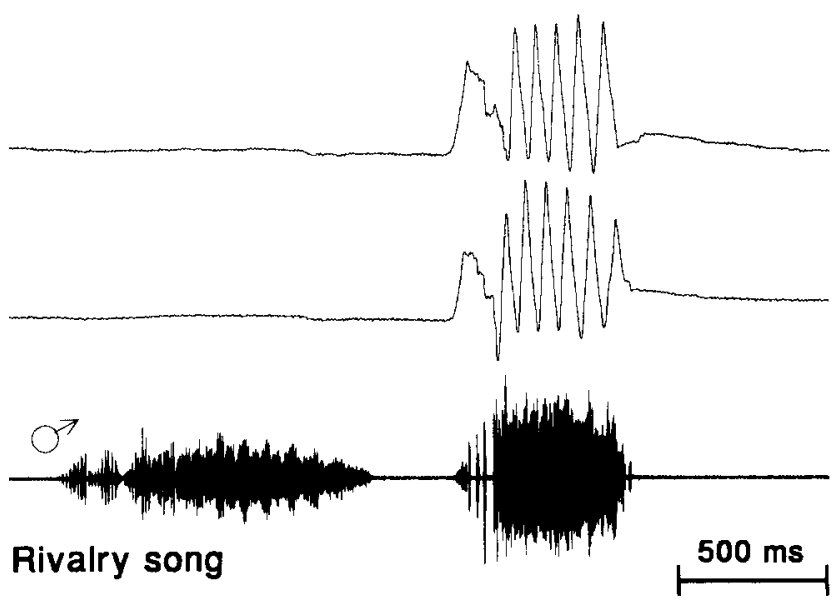

contains pulsed syllables (produced during downstrokes) separated by low-amplitude intervals. Each syllable comprises several pulses separated by gaps. Part B comprises ongoing noise only 
Table 1. Modal values of song phrases of Ch. dorsatus males at temperatures between 29 and $34{ }^{\circ} \mathrm{C}$

\begin{tabular}{|c|c|c|c|c|c|}
\hline Parameter & $\operatorname{Mean} \pm \mathrm{SE}$ & $\begin{array}{l}\text { Range } \\
\text { of means }\end{array}$ & $\begin{array}{l}\text { Range } \\
\text { of data }\end{array}$ & $\begin{array}{l}n \\
\text { (males) }\end{array}$ & $\begin{array}{l}n \\
\text { (data) }\end{array}$ \\
\hline $\begin{array}{l}\text { Pulse duration } \\
\text { in A-syllables }\end{array}$ & $9.1 \pm 1.1$ & $7.2-13.2$ & $5.1-16.0$ & 5 & 40 \\
\hline $\begin{array}{l}\text { Gap duration } \\
\text { in A-syllables }\end{array}$ & $7.3 \pm 1.5$ & $4.4-11.2$ & $1.4-14.7$ & 5 & 40 \\
\hline $\begin{array}{l}\text { Duration of } \\
\text { A-syllables }\end{array}$ & $84.0 \pm 5.5$ & $65-100$ & $\begin{array}{ll}51 & -129\end{array}$ & 6 & 23 \\
\hline $\begin{array}{l}\text { Pulse number } \\
\text { in A-syllables }\end{array}$ & $6.2 \pm 0.2$ & $5.3-7.0$ & $4-8$ & 11 & 48 \\
\hline $\begin{array}{l}\text { Intervals between } \\
\text { A-syllables }\end{array}$ & $114.9 \pm 7.4$ & $84-141$ & $66-148$ & 6 & 17 \\
\hline $\begin{array}{l}\text { Number of } \\
\text { A-syllables }\end{array}$ & $5.0 \pm 0.4$ & $3.0-6.7$ & $2-7$ & 11 & 376 \\
\hline Duration of $\mathrm{B}^{2}$ & $339 \pm 28$ & $\begin{array}{lll}285 & -378\end{array}$ & $\begin{array}{ll}- & \\
216 & -420\end{array}$ & $\begin{array}{r}3 \\
10\end{array}$ & $\begin{array}{c}(86) \\
10\end{array}$ \\
\hline
\end{tabular}

For number of A-syllables and duration of B, calling songs only have been evaluated. For other values some courtship songs have also been evaluated since no differences have been found between the two. All durations are given in milliseconds. The range of means gives the minimal and the maximal mean of the individuals, while the range of data gives the minimal and the maximal value of all data points

1 The first syllable of songs is sometimes very short and of low intensity. If that was the case, it has been omitted

2 The mean value has been calculated from the number of leg movements during part $A$, multiplied by the average duration of these movements from one phrase of the same individual. The 'range of data', however, is given from a data pool of single phrases from more (10) individuals pauses. This is referred to as "part B" of the song and lasts for about $280-380 \mathrm{~ms}$ (Table 1).

The switching from part $\mathrm{A}$ to part $\mathrm{B}$, therefore, is accompanied by changes in several aspects of the leg movements, namely (1) loss of the interruptions in the downstroke, (2) a doubling of the speed of the up and down movement and (3) changing the coordination of the legs from nearly simultaneous to alternating [for some details of the timing see Ronacher (1991)].

Calling songs are usually produced as a spontaneous singing activity without interactions with other individuals. In specific behavioural contexts (Faber 1932; Weih 1951 ; Jacobs 1953) slightly different songs comprising the same basic elements may be observed. One example is song alternation between a receptive female and a phonotactically approaching male. In this case the male songs become louder and the duration of part $B$ tends to increase. However, after a male has met a female which refuses to mate, so-called courtship songs are displayed: a long series of regular repetitions of less intense songs with the male sitting very close to the female. These phrases tend to contain more A-syllables and a slightly shorter B-part, although overall the songs may be shortened in later stages of the courtship. A dramatic change of the relative emphasis of part A and part B can be observed in so-called rivalry songs, which are produced by males in contact with other males (Fig. 1, right). In this case the number of A-syllables is strongly reduced (to one or zero), while the B-part is increased in intensity and duration (more, though faster leg movements).
Parameters in the male song eliciting the response song of the female

Behavioural experiments with females were performed to test whether and how females detect the specific structure of part-A syllables compared to part B (testing pulse duration, gap duration and pulse repetition rate, Fig. 2a, b). Furthermore, we examined whether the basic structure of part A, comprising syllables and lowamplitude intervals, is detected (Fig. 2c, d). In addition, models were presented with varying duration of part A and part B (Fig. 2e, f). Finally, the questions of whether both elements $A$ and $B$ are necessary to elicit female responses and whether the order of $\mathrm{A}$ and $\mathrm{B}$ is of importance were addressed (Fig. $3 a-c)$.

All artificial song models tested were simplified compared to natural song phrases in the following respects: all pulses of A-syllables and the complete part B have a constant noise amplitude. The tendency of increasing pulse numbers in one phrase (e.g. 3,5,5,6,6) has been ignored. The low-amplitude noise during part A upstrokes has been omitted and was replaced by "syllable pauses" (see top of Fig. 2).

Element $A$. When presenting models of the song with complete parts A and B, but containing A-syllables with different pulse durations, a peak response occurred for pulses of 5-8 ms duration (Fig. 2a). When varying the duration of gaps between the pulses (pulse duration $5 \mathrm{~ms}$ ), the response probability increased with gap durations greater than 2-4 ms and was maximal at $10 \mathrm{~ms}$ 

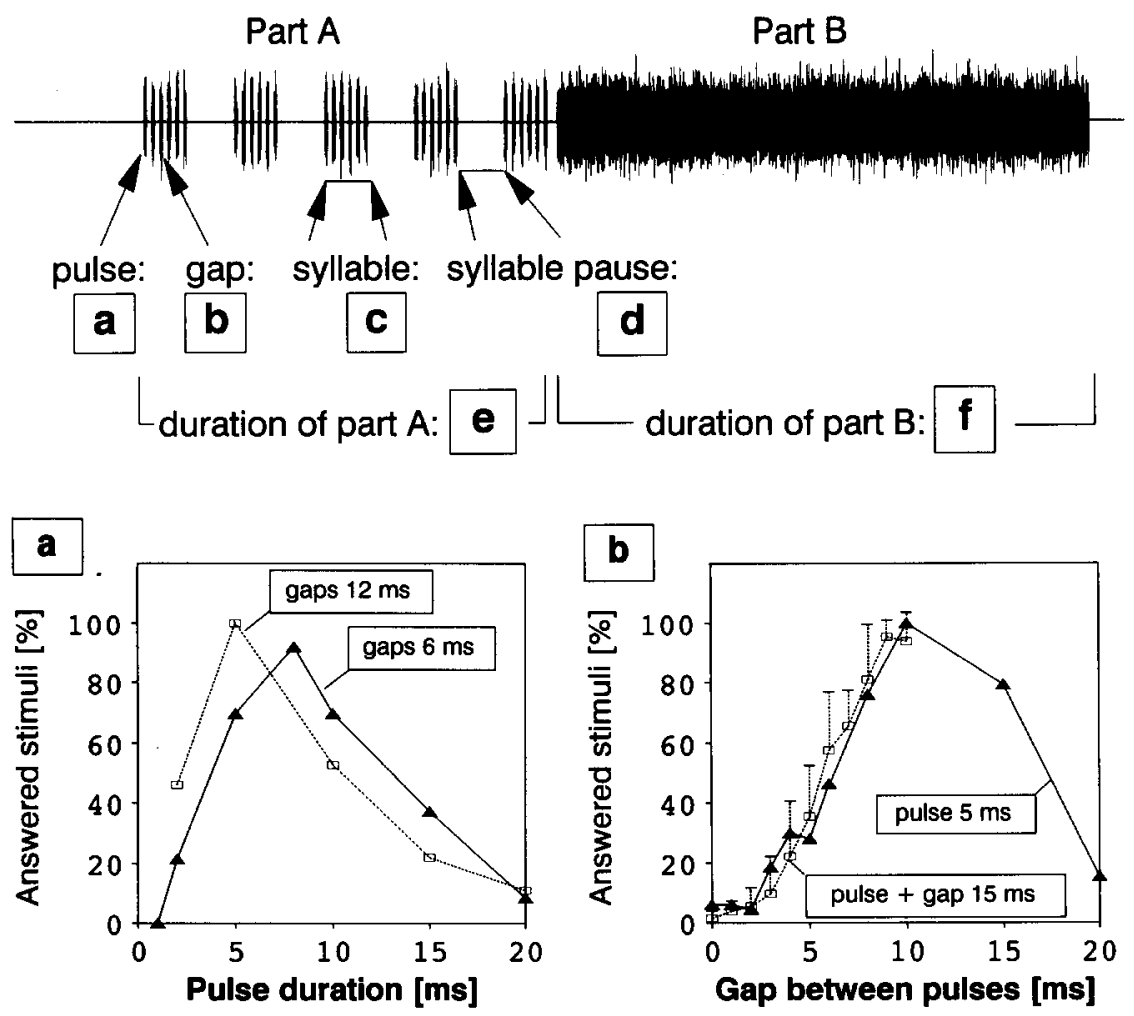

Fig. 2a-f. Model of a calling song and the female response functions for the respective parameters. Vertical lines, if inserted, are standard deviations representing the variability between individual females: a Pulses in element A. Responses of females to songs with varied pulse durations within the Asyllables. The two curves represent response functions with two different gap durations between the pulses, namely $6 \mathrm{~ms}$ (solid line) and $12 \mathrm{~ms}$ (broken line). 61 presentations per data-point, means of two females; b Gaps in element A. Responses of females to stimuli with varied gap durations within the pulsed syllables. Either the pulse duration was kept constant at $5 \mathrm{~ms}$ (number of pulses per syllable decreasing, solid line; three females, 218 presentations per datapoint; for 15 and $20 \mathrm{~ms}$ gaps data of only one female are shown, 104 presentations per data point), or the pulse repetition rate was kept constant with a $15-\mathrm{ms}$ period (pulse duration decreasing, dotted line; eight females, 600 stimuli per data point, positive standard deviations inserted only); c Duration of A-syllables. Responses of four females to A-syllables with varied number of pulses. Four A-syllables, pauses between syllables $85 \mathrm{~ms}$, pulses $5 \mathrm{~ms}$, gaps between pulses $10 \mathrm{~ms}, 540 \mathrm{~ms}$ part B. 120 presentations per data point; d Syllable-pauses in part A. Responses of four females to stimuli with varied pauses between A-syllables. Four A-syllables with six pulses, $540 \mathrm{~ms}$ part B. 121 presentations per data point; e Number of A-syllables. Responses of seven females to stimuli with varied number of A-syllables. A-syllables with six pulses, 90 -ms pause between syllables, 1000-ms B-part. 457 presentations per data point; $f$ Duration of part B. Responses of five females to stimuli with varied duration of part B. Five A-syllables with six pulses, 90-ms pause between syllables. 405 presentations per data point
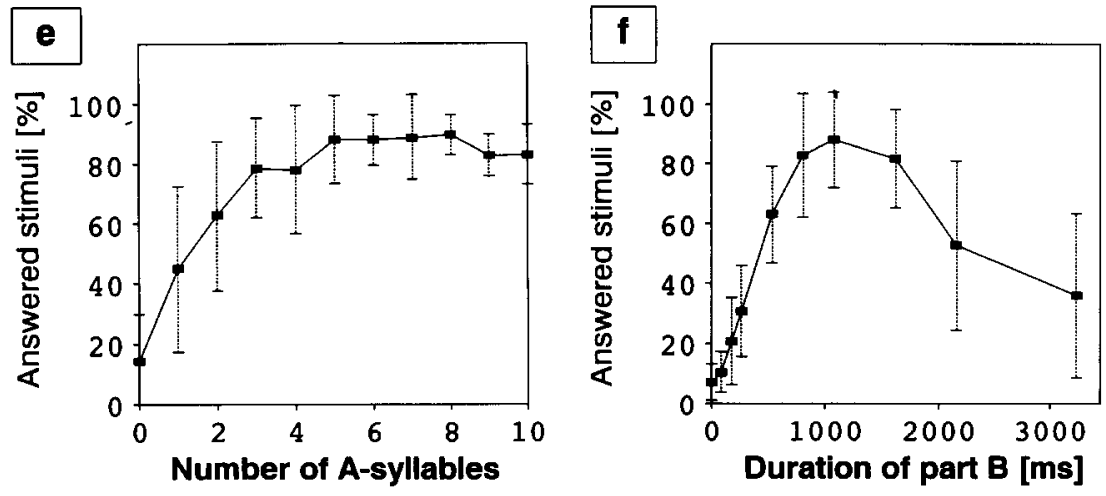

(Fig. 2b, solid curve). The female response functions obviously were not influenced by the changing pulse repetition rate, since the same results were obtained when the pulse repetition rate was kept constant (pulse + gap $=15 \mathrm{~ms}$; Fig. 2b, dotted curve). The same argument holds true for the pulse duration, which was constant for the solid curve in Fig. $2 \mathrm{~b}$, but changing for the dotted curve. Therefore, gaps seem to be the main feature by which females recognize element $\mathrm{A}$. Moreover, female preferences lie well within the range of modal values of natural songs around $30^{\circ} \mathrm{C}$ (see Table 1).

The duration of and intervals between A-syllables 


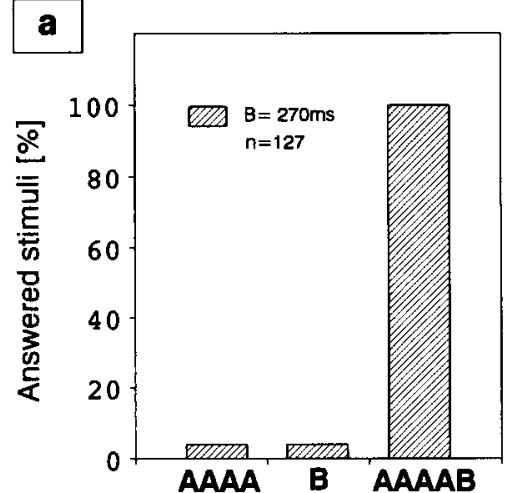

Fig. 3a-c. Response frequencies of female $C h$. dorsatus to stimuli combining part $A$ and part $B$ in different ways: a Presence of $A$ and B. Responses of six females to song models consisting of part A only (four pulsed syllables), of part B only (270-ms uninterrupted syllable) or the combination of both. 127 presentations per data point. For statistics see text; $\mathbf{b}$ Order of A and B. Responses of eight (light columns) and five (dark columns) females to a model song and the temporal inverse stimulus. A stimulus comprises four pulsed Asyllables and a 540-ms (light) or a 1000-ms (dark) part B. 237

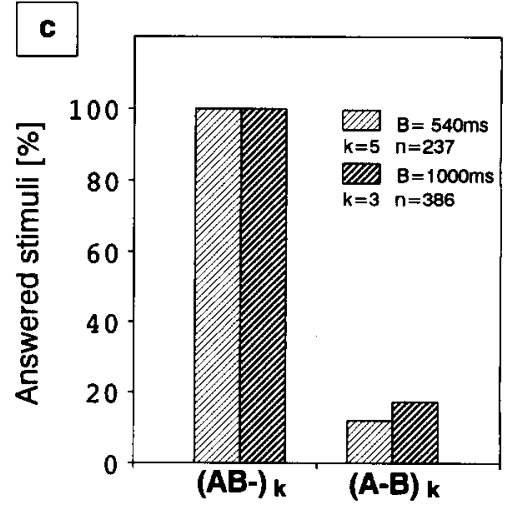

(light) and 386 (dark) repetitions per data point. For statistics see text; c Artificial repetitions of A and B. Responses of six (light columns) and five (dark columns) females to combinations of one A-syllable and $270-\mathrm{ms}$ part B (light columns) or 1000 -ms part B (dark columns), each combination being five times (light) or three times (dark) repeated. The pauses between $A$ and $B$ are 20 and $90 \mathrm{~ms}$ with the longer pause being indicated by a dash (AB-, A-B). 188 (light) and 386 (dark) repetitions per data point. For statistics see text

containing pauses (combinations of 3-, 5- and 10-ms pauses tested), and in three of four females the stimulus with the greatest number of pauses was least effective (data not shown).

Therefore, the main test regarding element $B$ was the variation of its duration (Fig. 2f). The females showed maximum responses between 800 and $1600 \mathrm{~ms}$ B-duration. This is surprising, since in male calling songs the B-part usually ranges from 280 to $380 \mathrm{~ms}$ only (Table 1).

Presence and order of part $A$ and part $B$. Are both elements of the calling song necessary to evoke a female response? Test stimuli were composed according to values found in natural songs with four A-syllables and a B-part of $270 \mathrm{~ms}$ duration. Figure 3a clearly demonstrates that parts A and B were not effective if presented alone. This was true for all six females tested [significant differences at the $1 \%$ level $(1 x)$ or $0.1 \%$ level $(4 x)$, only one result not significant at the $5 \%$ level due to small sample size]. The first data points in Fig. 2e and in Fig. $2 \mathrm{f}$ corroborate these findings.

Is the order of the two elements important for the female response? Two test series were made with stimuli of four A-syllables and a 540-ms or a 1000-ms B-part. In each case a stimulus with natural order $A B$ was compared to one with inversed order BA (the pause between $A$ and $B$, or B and A, respectively, was $20 \mathrm{~ms}$ ). As can be seen from Fig. $3 b$, the natural order AB is necessary for a stimulus to be effective. All of 13 females tested responded much more strongly to $\mathrm{AB}$ than to $\mathrm{BA}(12$ females with significant differences at the $0.1 \%$ level or higher, 1 female at the $1 \%$ level).

The question of whether females would be confused by artificial repetitions of the type ABAB was also tested. The results, however, were unequivocal in this case, although the order of A and B was merely defined by the pauses between them. Two similar test series were made: 
either a $20-\mathrm{ms}$ pause separated $A$ and $B$ and a $90-\mathrm{ms}$ pause separated $B$ and $A(A B-A B-. .$.$) or the pause dura-$ tions were reversed (A-BA-BA...; for more details see legend of Fig. 3c). Figure $3 \mathrm{c}$ presents the results from 11 females; again, all females responded more strongly to the "AB-" series than to the "A-B" series [significant differences at the $5 \%$ level $(2 x)$, at the $1 \%$ level $(3 x)$, and the $0.1 \%$ level $(6 \mathrm{x})]$.

In contrast to these artificial repetitions, the variation of the pause between A and B was less critical in a more natural song model with four A-syllables and a $540-\mathrm{ms}$ part B: pauses up to about $100 \mathrm{~ms}$ between $A$ and $B$ were accepted with optimal efficiency and the responses only slowly decreased with increasing pauses (data not shown). It seems, therefore, that the grouping into ABor BA-units resulting from different durations of the two pauses and not the absolute pause durations produced the results shown in Fig. 3c.

\section{Discussion}

Chorthippus dorsatus females discriminate between the two different elements of the male song, pulsed syllables (part A) and continuous noise (part B). They do this mainly by listening to the gaps between the pulses. These gaps must be longer than about $5 \mathrm{~ms}$ to be sufficiently effective. Furthermore, the females expect a gross separation of part A into syllables and intervals. Part B is most effective comprising an ongoing noise without interruptions.

Our experiments with females demonstrate that for mate recognition not only the presence of both elements is decisive, but also their order. Therefore, Ch. dorsatus differs from species with two-element songs such as the frog Eleutherodactylus coqui (Narins and Capranica 1976, 1978) and the cricket Teleogryllus oceanicus (Pollack and Hoy 1979, 1981; Pollack 1982). In these two species the two different elements seem to be directed to different receivers, rival males and receptive females. The communication system of the frog Physalaemus pustulosus may be comparable to that of Ch. dorsatus, since females of this frog species prefer male calls which contain both of two possible elements, a "whine" and several "chucks" (Ryan and Drewes 1990; Kirkpatrick and Ryan 1991). In the related species Ph. coloradorum females even prefer the two-note song, although their males only sing one-note songs.

\section{Neuroethological aspects}

Ch. dorsatus females detect gaps in pulsed syllables of the male song (Fig. 2b). A similar performance - although with a much steeper response function - has been thoroughly investigated in another grasshopper, Ch. biguttulus [behaviour, von Helversen (1979); and neuronal level, Ronacher and Römer (1985), Ronacher and Stumpner (1988), Stumpner et al. (1991)]. Several auditory neurons, which respond differently to stimuli with and without short gaps within noise syllables, have been described at the thoracic level. Neural elements, most probably homologous to those described for Ch. biguttulus, have been found in other species of the genus Chorthippus (A. Stumpner, unpublished observations) as well as in Locusta migratoria (Ronacher and Stumpner 1988). Therefore, it is very likely that $C h$. dorsatus possesses these thoracic neurons as well.

However, the behavioural effects of these gaps are quite different in the different species: while the response of Ch. biguttulus females is inhibited by gaps and no known behaviour of L. migratoria is correlated to gap detection, the response of $C h$. dorsatus females is elicited by stimuli which do have gaps in part-A syllables but which do not have gaps in part B. If the same neuronal elements are used for detection of "necessary" and "destructive" gaps, they must be connected to the final neuronal filters for song pattern detection in ways differing not only between species, but also within Ch. dorsatus for discrimination between pattern $\mathrm{A}$ and pattern $\mathrm{B}$.

Furthermore, some kind of coupling has to take place between the neurons processing the two song elements, since both have to be present in the correct order to evoke responses of the female. Interestingly, in artificial repetitions of the two elements (Fig. 3c) pauses of 20 and $90 \mathrm{~ms}$, respectively, were sufficient to define the order, i.e. the direction of the coupling, while in more natural models much longer pauses between the two elements were tolerated. This raises questions which could be addressed to auditory neurons in electrophysiological experiments.

\section{Evolutionary aspects: role of sexual selection}

The parameter values most effective for the female responses were found to correspond well to the values produced by singing males, particularly for the fine structure of A-syllables. This may be expected if sexual selection links properties of signal and receiver by mutual selective pressures. However, there is one interesting exception: whereas males usually produce just as many A-syllables as necessary to reach the saturation level of the female response function (Table 1 and Fig. 2e), they seem to be unable to produce B-parts satisfying the requirements of their females (cf. Table 1 and Fig. 2f); songs in which part $B$ was of $800-1600$ ms duration were much more effective than songs with the natural range of part $B$ (around $350 \mathrm{~ms}$ in calling songs; up to $650 \mathrm{~ms}$ in contact with other individuals). With regard to the duration of part B, it is clear that "supernormal stimuli" exist which are more effective in triggering a female's response than natural songs.

Since the duration of B-parts seems to be relatively variable in male songs and since $B$-parts longer than $650 \mathrm{~ms}$ (at $30^{\circ} \mathrm{C}$ ) were never observed, it is possible that males are unable to produce longer B-parts. During production of part $B$ the speed of the leg movements is relatively high (leg cycle $10-17 \mathrm{~Hz}$ but with large amplitude) and the production of these movements (while rubbing the legs against the forewings) may be costly and exhaustive. Interestingly, in experiments involving surgi- 
cal operations on the metathoracic ganglion of the same species, some males were induced to sing long series of A-syllables but no male exhibited songs with prolonged B-parts [B-parts were often even shortened to below $200 \mathrm{~ms}$ or were missing completely; Ronacher (1991) and pers. comm.].

Therefore, females of Ch. dorsatus may use the B-part as the most costly element to test a male's vigour. This would agree with the conclusion of Maynard Smith (1991) that in an evolutionarily stable system, in a context where a conflict of interest between the sexes is obvious, only costly signals will-remain "honest" (and should be "superoptimizable" - authors' comment). However, signals which are used for species identification serve the interests of sender and receiver and should be honest in any case. "Supernormal" stimuli within communication systems should be investigated under this aspect.

In close relationship with $C h$. dorsatus there are two other species, Ch. dichrous and Ch. loratus. These species have the same two elements in their songs as $C h$. dorsatus, and the differences between calling songs of these species are to be found mainly in the number of A-syllables and to a minor degree in the duration of part $B$ (A. Stumpner and O. von Helversen, unpublished observations). In the next relationship, probably as a sister group, is the Ch. parallelus group [e.g. Jacobs (1953) and von Helversen (1986); for relations within the Ch. parallelus group see Butlin and Hewitt (1987)]. In the Ch. parallelus group a calling song exclusively contains typeA syllables. However, Ch. parallelus produces a rivalry song by moving the hindlegs in anti-phase, which is similar to the stridulation of $\mathrm{Ch}$. dorsatus during part B (e.g. Faber 1932; Jacobs 1953). Since Ch. dorsatus also emphasizes part B and almost completely reduces part A in rivalry songs, it seems that part B is primarily directed at other males. The starting point of evolution, therefore, could have been a situation similar to that of Eleutherodactylus coqui and Teleogryllus oceanicus, with two elements in a song, one produced for females and one for other males.

Why did the females of the Ch. dorsatus group start to require a two-element song from the males? If sexual selection is the main driving force for the evolution of these communication systems, the following hypothesis could be proposed: it might have been helpful for females to listen not only to calling songs (element A) but also to rivalry songs (element $B$ ), since both of them indicate the presence of males of their own species. Therefore, it might have been advantageous for females to respond to both elements, A and B. Alternatively, following up Fisher's (1930) ideas on the choices of females, for which the reproductive success of their male offspring should be of importance, one might postulate the following: if males sang two elements and females responded to either of both elements, a selective pressure on females would have arisen to choose males which produced both elements together, since these males (and - if genetically determined - most probably their male offspring) would attract females which respond more strongly to part A and females which respond more strongly to part $\mathrm{B}$. This would be a mechanism to change from a logic coupling
A or $\mathrm{B}$ in the receiver to a coupling of $\mathrm{A}$ and $\mathrm{B}$. Obviously, in the course of such an evolution, in this population only the genes of males singing $\mathrm{AB}$ would survive due to the selective pressure of the receiver.

Introducing the $\mathrm{AB}$-system for sender and receiver would also serve as a premating isolating mechanism against other species of the $C h$. parallelus group which use only A-syllables in their calling songs. Therefore, the selective pressure on pregamic isolation might have been important during the development of the two-element system of $C h$. dorsatus and related species.

Acknowledgements. We thank Helmut Kriegbaum and Dagmar von Helversen for supplying some of the animals and Bernd Ronacher for stimulating discussions. He, Norbert Elsner and Dagmar von Helversen kindly critically read the manuscript.

\section{References}

Butlin RK, Hewitt GM (1987) Genetic divergence in the Chorthippus parallelus species group (Orthoptera: Acrididae). Biol J Linn Soc 31:301-310

Elsner N (1974) Neuroethology of sound production in gomphocerine grasshoppers. I. Song patterns and stridulatory movements. J Comp Physiol 88:67-102

Faber A (1932) Die Lautäußerungen der Orthopteren II. (Untersuchungen über die biozönotischen, tierpsychologischen und vergleichend physiologischen Probleme der Orthopterenstridulation. Methodik der Bearbeitung und Auswertung von Stridulationsbeobachtungen. Einzeldarstellungen.) Z Morphol Oekol Tiere 26:4-93

Faber A (1953) Laut- und Gebärdensprache bei Insekten (Orthoptera). Mitt Staatl Mus Naturk Stuttgart, Stuttgart

Faber A (1957) Über den Aufbau von Gesangsformen in der Gattung Chorthippus und über phylogenetische Gemeinsamkeiten bei Stridulations- und anderen Bewegungsformen. Stuttg Beitr Naturkd 1:1-28

Faber A (1960) Form, Ableitung und Bedeutung von Stridulationsweisen im Verwandtschaftskreis um Chorthippus longicornis. Stuttg Beitr Naturkd 32:1-12

Fisher RA (1930) The genetical theory of natural selection. Oxford Univ Press, Oxford

Helversen D von (1972) Gesang des Männchens und Lautschema des Weibchens bei der Feldheuschrecke Chorthippus biguttulus L. J Comp Physiol $81: 381-422$

Helversen D von, Helversen O von (1983) Species recognition and acoustic localization in acridid grasshoppers: a behavioral approach. In: Huber F, Markl $\mathrm{H}$ (eds) Neuroethology and behavioral physiology. Springer Berlin Heidelberg New York, pp 95-107

Helversen $O$ von (1979): Angeborenes Erkennen akustischer Schlüsselreize. Verh Dtsch Zool Ges 1979:42-59

Helversen $O$ von (1986) Gesang und Balz bei Feldheuschrecken der Chorthippus albomarginatus-Gruppe (Orthoptera: Acrididae). Zool Jb Syst 113:319-342

Helversen O von, Elsner N (1977) The stridulatory movements of acridid grasshoppers recorded with an opto-electronic device. J Comp Physiol 122: 53-64

Helversen O von, Helversen D von (1987) Innate receiver mechanisms in the acoustic communication of orthopteran insects. In: Guthrie DM (ed) Aims and methods in neuroethology. Manchester University Press, Manchester, pp 104-150

Huber F, Kleindienst H-U, Moore TE, Schildberger K, Weber T (1990) Acoustical communication in periodical cicadas: neuronal responses to songs of sympatric species. In: Gribakin FG, Wiese K, Popov AV (eds) Sensory systems and communication in arthropods. Birkhäuser, Basel, pp 217-228 
Jacobs W (1953) Verhaltensbiologische Untersuchungen an Feldheuschrecken. Z Tierpsychol, Beiheft 1

Kirkpatrick M, Ryan MJ (1991) The evolution of mating preferences and the paradox of the lek. Nature 350:33-38

Komarova GF, Dubrovin NN (1973) A comparative study of the acoustic signals of two sibling species of grasshoppers Chorthippus dorsatus Zett and Ch. dichrous Ev. Zh Obshch Biol $34: 571-574$

Maynard-Smith JM (1991) Honest signalling: the Philip Sidney game. Anim Behav 42:1034-1035

Narins PM, Capranica RR (1976) Sexual differences in the auditory system of the tree frog Eleutherodactylus coqui. Science 192:378-380

Narins PM, Capranica RR (1978) Communicative significance of the two-note call of the tree frog Eleutherodactylus coqui. J Comp Physiol 127: 1-9

Otte D (1972) Simple versus elaborate behavior in grasshoppers: an analysis of communication in the genus Syrbula. Behaviour 42:291-322

Pollack GS (1982) Sexual differences in cricket calling song recognition. J Comp Physiol 146:217-221

Pollack GS, Hoy RR (1979) Temporal pattern as a cue for species-specific calling song recognition in crickets. Science 204: 429-432

Pollack GS, Hoy RR (1981) Phonotaxis to individual rhythmic components of a complex cricket calling song. J Comp Physiol $144: 367-373$

Ronacher B (1991) Contribution of abdominal commissures in the bilateral coordination of the hindlegs during stridulation in the grasshopper Chorthippus dorsatus. J Comp Physiol A 169: 191-200

Ronacher B, Römer H (1985) Spike synchronization of tympanic receptor fibres in a grasshopper (Chorthippus biguttulus L. Acrididae): a possible mechanism for the detection of short gaps in model songs. J Comp Physiol A 157:631-642

Ronacher B, Stumpner A (1988) Filtering of behaviourally relevant temporal parameters of a grasshopper's song by an auditory interneurone. J Comp Physiol A 163:517-523

Ryan MJ, Drewes RC (1990) Vocal morphology of the Physalaemus pustulosus species group (Leptodactylidae): morphological response to sexual selection for complex calls. Biol $\mathbf{J}$ Linn Soc 40:37-52

Sachs L (1984) Angewandte Statistik. Springer, Berlin

Schmidt G, Schach G (1978) Biotopmäßige Verteilung, Vergesellschaftung und Stridulation der Saltatorien in der Umgebung des Neusiedler Sees. Zool Beitr 24:201-308

Stumpner A, Ronacher B, Helversen O von (1991) Auditory interneurons in the metathoracic ganglion of the grasshopper Chorthippus biguttulus. II. Processing of temporal patterns of the song of the male. J Exp Biol 158:411-430

Vedenina VY (1990) Responses of sympatric acridid species to natural and artificial sound signals. In : Gribakin FG, Wiese K, Popov AV (eds) Sensory systems and communication in arthropods. Birkhäuser, Basel, pp 366-370

Vedenina VY, Zhantiev RD (1990) Recognition of acoustic signals in sympatric species of locusts. Zool Zh 69:36-45

Weih S (1951) Untersuchungen über das Wechselsingen (Anaphonie) und über das angeborene Lautschema einiger Feldheuschrecken. Z Tierpsychol 8:1-41 